\title{
DEVELOPMENT OF EVALUATING THE SERVICE METHODS QUALITY
}

\author{
Usserbayeva M.A. \\ Al-Farabi Kazakh National University \\ Almaty, Republic of Kazakhstan \\ +77014499878, madina-_94@mail.ru
}

This paper analyzes the effectiveness of the quality system in the services sector, suggests ways to improve and enhance the quality of customer service on an example of a single organization. The methods of quality assurance for the enterprise in general and specifically are based on the methodology developed by the author for calculating the quality of services. The literature describes a number of ways to measure customer satisfaction, so I used the all known methods which are used in domestic and foreign practice to develop of recommendations to improve the quality of service in the resort. But, unfortunately, they do not cover all the required amount of information, so I proposed a method in which the known methods used, as well as the formula for the accurate assessment of the quality of service applied. This formula is first proposed to determine the quality of services provided, without a large number of calculations and analyzes. For this we introduce the variable $X$ - customer satisfaction, which means the ratio of consumers estimate obtained during the survey to guide the assessment, expressed in \%. The smaller the determined value, the greater the discrepancy between the expectation of the organization and customer data.

The problem of the quality of service and customer satisfaction research is relevant and the relevance of the research areas is constantly increasing, which is determined by a number of factors that characterize modern markets, such as constantly increasing competition among suppliers and a high level of consumer awareness due to more available information about products and services. In addition, the development of the economy is moving towards increasing the service component in the total volume of produced goods, and employment.

To this day variety of methods evaluation of the quality of service is developed. Among them it is necessary to allocate five methods, which are conceptually and methodologically different from each other: the method of critical cases, SERQUAL method, SERVPERF method, INDSERV method Cano method.

The method of "critical cases" (critical incidents technique) is based on the empirical study of cases of interaction between the consumer and the representative of the service provider (employee of a service company). The criteria for classification of a service interaction to critical cases are the following:

- the presence of the interaction between the consumer and the employee of the service provider;

- significant case with the consumer's point of view (a very high degree of satisfaction / dissatisfaction, memorable customer);

The practice of the method manifests the lack of it - the need for a long time in the collection and analysis of information on critical cases from consumers, which includes a description and assessment.

SERQUAL method. The need for a more formalized quality evaluation methods of service as compared to the methods of critical cases determined the appearance of SERVQUAL method [1].

A.Likert scale with seven intervals ranging from "Strongly Disagree" to "Strongly Agree", by which the respondent has to give two assessments: their expectations and their perception of the service rendered to each service attribute is used for estimation. Dual rating is due to the fact that the method used the difference between the expectation of the customer and his perception to assess each attribute. SERVQUAL method was widespread in mind simplicity and clarity. However, use of the differences between consumer expectations and their perception of the (so-called "differentiated approach") in evaluating the quality of service reduces the reliability of the data because of the psychometric properties of the measurement (interference consistently measured indicators) [2]. 
Based on the method SERVQUAL J.Cronin and S.eylorom was designed SERVPERF method (SERV of the service, ("Service") by PERF and performance («performance of the action"), which means "the provision of services"). This method avoids the negative impact of the differential approach to the reliability of data obtained because of applying the method in connection with which the quality of service measurement procedure is excluded stage measuring consumer expectations. In other words, SERVPERF method only measures consumer perception of quality of the provided service. The author without changes with respect to the original method SERVQUAL used 5 service quality measurements and the corresponding attribute 22 [3]. Attempts to use SERVQUAL and SERVPERF method for assessing the quality of service in the corporate sector have shown that these methods are arranged in such a way that take into account mainly the personal perception of service quality and not appreciated by the consumer companies. To solve this problem S.Gounarisom have developed a method INDSERV, which is based on two approaches to the study of the quality of service perceived by the consumer:

- consideration of the perceived quality of service as a final and independent indicator. This approach involves obtaining direct assessment of the perceived quality of the consumers by the survey;

- consideration of the perceived quality of service as a multi-level (hierarchical) indicator.

As previously outlined methods generally considered attitude of the staff to the customers.

But it is necessary to take into account the serviceability of equipment, the competitiveness of the organization, the ability of the company to enter the world market, and, of course, adjust the ratio of the working personnel to customers. First, you need to conduct a survey to customers and to guide, in order to understand what consumers are not satisfied, and they expect representatives of the management. Example used the questionnaire proposed in Table 1.

This method uses the following ratio: $50 \%$ - evaluation of the quality of personnel; $30 \%$ - equipping the organization with the necessary equipment; $20 \%$ - the opinion of a third party not involved in the service process. This will allow evaluating objectively the possibility of the company and its competitiveness. Each organization interested in its further development, she has the right to determine the criteria according to which the survey will be conducted.

The questions in the questionnaire developed by the author include the following indicators: tangibility (tools / equipment / tools / personnel necessary to accomplish this task); reliability (the client receives the desired results consistently over and over again); responsiveness (service provider - friendly, fast and accurate); guarantee (the client is in the hands of competent performers); empathy (caring, the customer receives service and individual approach and attention), competitiveness (the survey is conducted outside the enterprise from bystanders).

After receiving the results of each indicator is assigned by a degree of validity. The maximum number is 10 . The distribution of the degree of weight determined according to expert's skills in each case individually. In the course of this survey it is possible to identify shortcomings, because the denominator of the fraction of our formula will not be equal to 10 . Annex 1 shows an example of a questionnaire to fill in the sanatorium patients, where the research took place.

For decision-making, adopted based on intuition and experience of individual managers, academic, formalized management techniques, based on consideration of the formation used causation quality of products (Figure 1). 
Table1

The questionnaire for assessing the services quality

\begin{tabular}{|c|c|c|c|c|}
\hline 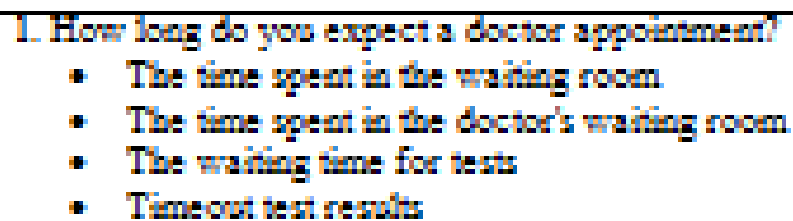 & $\begin{array}{l}\text { Tery } \\
\text { hert } \\
\frac{9}{9} \\
0\end{array}$ & $\frac{9}{8}$ & 9 & $\begin{array}{l}\operatorname{Tog} \\
\log \\
0 \\
0 \\
0\end{array}$ \\
\hline $\begin{array}{l}\text { Sd you have troble making an a } \\
\mathrm{O} \text { No }\end{array}$ & \multicolumn{4}{|c|}{ (moecifv plesse) } \\
\hline
\end{tabular}

\begin{tabular}{|c|c|c|c|}
\hline $\begin{array}{l}\text { 3. How do gou awen be chanes of geting besth } \\
\text { care? }\end{array}$ & Excetlent & Good & Motgood \\
\hline 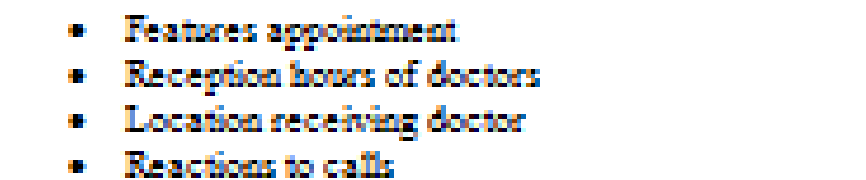 & 8 & 9 & 8 \\
\hline
\end{tabular}

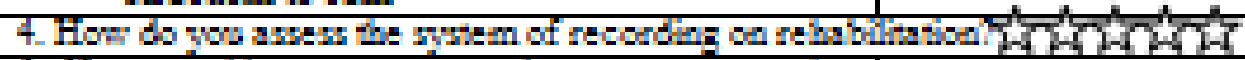

5. How moold you rate you doctor, ache or ober mediesilgersonet?

- They linsea and give de atection to wo

- Yos are mell treated and be give you adwoes

- They behave friendly and belp

- They ansers you goestion

6. How do you awex be technical waff?

- Behave friendly and if aecewary belp the patient

- Repod to patent quenten

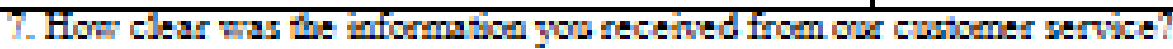

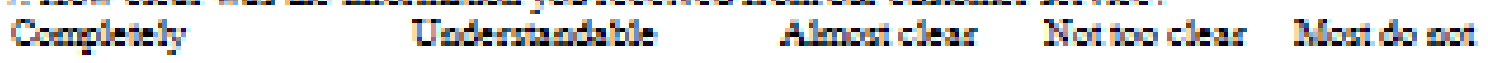
rodemand

$\begin{array}{ccccc}\text { rederandable } & 0 & 0 & 0 & 0\end{array}$

Exestent Good Notgood Bad bowally?

- Neamen acd cleanlioes

hare I tend I tead $D$ to

to agree to disgres agre

- Easy orientatica ta the bogital

- Comerifoce and rafey

- Personal roce

9. Woudd you recommend wa to you tamly or frends garties?

Tol What do you ke derke?

Thant you for you ansers!

Picture 2 shows the results of the survey at a particular enterprise by the developed technique. 


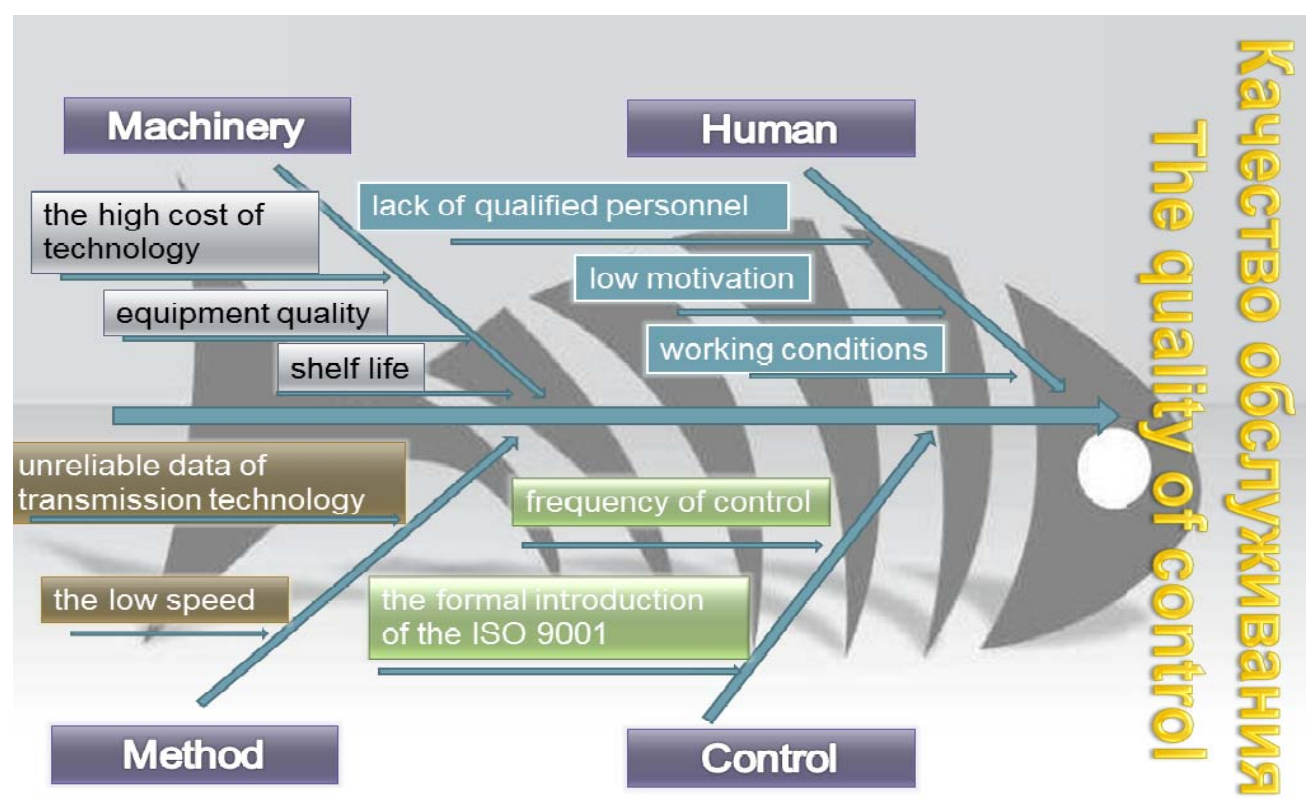

Picture 1. "Fishbone Diagram"

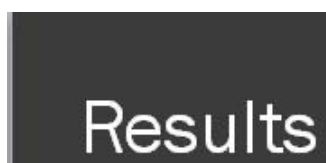

- Real answers of patients before

appliance of

recommendations

- Our

expectations

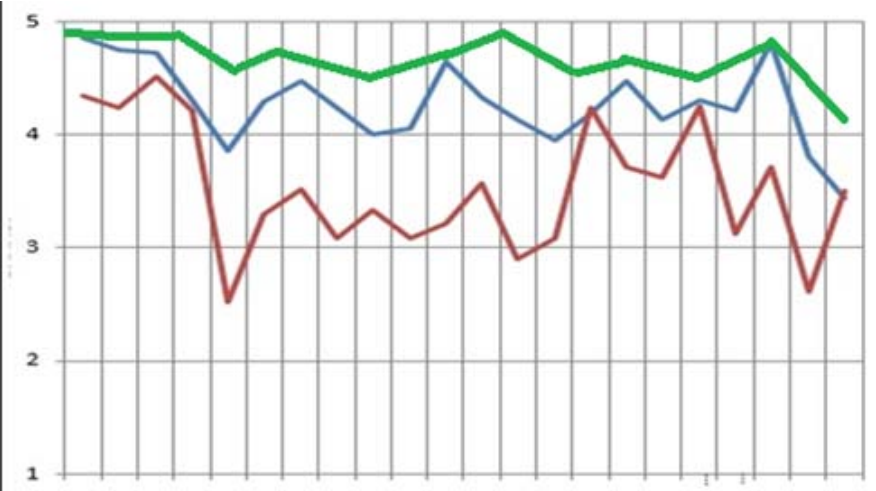

- Real answers of patients after

appliance of

recommendations
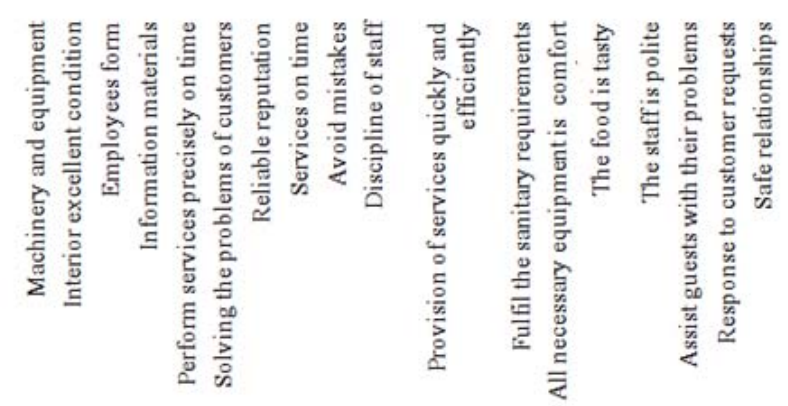

Picture 2. Results of the questionnaire

\section{BIBLIOGRAPHY}

1. Parasuraman A., Zeithaml V. A., Berry L.L. A conceptual model of service quality and its implications for future research. Journal of Marketing, Vol. 49 No. 3, 1985, 41-50.

2. Kotler F. Management and Marketing - M: LTD Case 2002.

3. Gounaris S. Measuring service quality in b2b services: an evaluation of the SERVQUAL scale vis-a-vis the INDSERV scale. Journal of Service Marketing 19/6 (2005) Emerald Group Publishing Limited, 421-435. 